\title{
Estimation of Labour Damage for Disruption and Prolongation Claims Using Measured Miles Analysis
}

\author{
Tewodros Goitom \\ Department of Construction Technology and Management, Addis Ababa Science and Technology University, Addis Ababa, Ethiopia \\ Email address: \\ Theomangoitom93@gmail.com,gsr051911cotm@aastu.edu.et

\section{To cite this article:} \\ Tewodros Goitom. Estimation of Labour Damage for Disruption and Prolongation Claims Using Measured Miles Analysis. Advances in \\ Sciences and Humanities. Vol. 6, No. 4, 2020, pp. 94-100. doi: 10.11648/j.ash.20200604.11
}

Received: July 16, 2020; Accepted: August 4, 2020; Published: November 24, 2020

\begin{abstract}
Accurate quantification of lost productivity on contractors due to disruption by the Client is one of the major headache in the field of claim analysis. Estimation of lost productivity is one of the contentious task under claim management and very challenging to attain accurate loss in productivity. There are a number of methods provided for estimation of damages caused by lost productivity, but among them Measured Miles method is known for its accuracy and preferred by courts and boards. Measured Mile method works by comparing actual productivities obtained during two different sessions at which the company was exercising its full capacity and those times where the progress of the work was impaired by the Employer. In order to show the procedure employed to conduct a Measured Miles approach to quantify a disruption and prolongation damages a case study a claim occurred at Great Ethiopian Renaissance Dam Project is carried out. Finally, the study shows how much Measured Miles approach is helpful for equitable decision-making and helped the Employer to protect himself from unnecessary expense caused by biased decision.
\end{abstract}

Keywords: Measured Miles Approach, Disruption, Prolongation, Modified Total Cost

\section{Introduction}

The occurrence of claim in almost every construction projects is imminent. There are several causes can potentially hinder the normal progress of projects. Disruption and prolongation claims are very common types of claims. Disruption claim is a claim happened due to the impediment of the contractor against running the works as per the plan and causing inefficiency. However, prolongation claim can be simply defined as a closure of a project or part of a project for a period.

The occurrence of disruption causing events that let loss in productivity are often difficult to detect and quite challenging to quantify the damages. Supporting and evaluating cost overrun claims because a contractor has suffered labor productivity problems are difficult undertakings [1]. Damages estimated for claims comes in consequent to disruption and prolongation causing events are known as disruption and prolongation damages. There are various methods provided by Society of Construction Law and Association for the Advancement of Cost Engineering (AACE) for the computation of damages for claims occurred due to lost productivity. Among these methods, Measured Miles approach is the most preferred method by courts and boards.

The approach for quantifying the impact of disruption which has been relied on by the court more than any other in recent years is the measured mile approach [2]. Measured miles approach is relatively most accurate method than the other common types of methods, like Total Cost Method or Modified Total Cost Method. The method works by comparing actual productivities recorded during the period on which the project has been impaired by the Employer or Employer's other Contractor.

\section{Literature Review}

A claim is simply an assertion of a party's right under the terms of a contract or under law [3]. In case of the construction industry, a claim could be defined as a demand by a contractor for an EoT and remuneration of money for a lost budget due to the default of the Employer or Employer's other Contractor. There are a number of ways to classify construction claims. Construction claims can be classified 
depends on the claiming party, rights claimed, legal basis, and characteristics of causing factors. Depending on the claiming party, a construction claim can be classified as owner claim or contractor claim. A claim for extension of time or compensation of money or item are types of claims classified depends on the right claimed. According to Zaneldin's in-depth investigation on the types, natures and relationships between various claim causing events, after conducting extensive studies on construction projects found in UAE, he classified claims into six main types: contract ambiguity claims, delay claims, disruption claims, acceleration claims, change claims, extra work claims and differing site condition claim [4].

\subsection{Delay Claim}

A "delay" in the construction context can be specifically defined as any failure to complete a specific construction activity within the time planned for it [5]. In the same way, when a party ask for a time extension, monetary compensation, or both the phenomenon is called delay claim. Most writers classify delay according to responsibility and compensability into four categories: excusable, nonexcusable, compensable, and concurrent delays [6].

Excusable delay -Bin Mohamad has defined Excusable delay as a delay where neither the client nor the contractor is deemed responsible. When this type of delay is encountered, only a time extension will be warranted since there are no grounds for damages [7].

Non-Excusable delay - events that foreseeable and within the capacity of the contractor. Delays occurred due to the default of the contractor not to carry out the expected works as per the contract; the contractor will become liable for every loss coming consequently. In such cases, the contract usually allows the client to claim for entitlement of damage and the amount of the damage will be stated under the contract [7].

Compensable delay - A delay that is compensable to a contractor is one that was not anticipated when the contract was made and is due to some inaction or action for which the owner or those working under him or her are responsible. In such a situation, the contractor can recover money damages from the owner to cover the extra costs incurred as a result of the delay, and also receive a time extension [8].

Concurrent delay - refers to the complex situation where more than one event occurs at the same time, but where not all of those events enable the contractor to claim an extension of time or to claim loss and expense. According to Gibson, there is no single generally accepted definition of concurrent delay [9]. A narrow definition of concurrent delay is 'true concurrency'. True concurrency is where the employer and contractor delay events occur at the same time and cause a delay to progress for the same period sharing the same start and finish dates, either of which, in the absence of the other, is likely to cause the same delay to the completion of the works.

\subsection{Delay Damage}

Damage is a compensation for an innocent party for the loss or harm suffered as a result of another party's breach of contract. Hence, Delay damage is a compensation money payed for losses came in consequent to delay occurred to the project due to the breach of the other party. The generally accepted rule is that contractual damages should be sufficient to compensate for such losses as may fairly and reasonably be considered as arising from the breach of contract [10].

\subsection{Disruption Claims}

Disruption are often treated as being the same thing to delay. However, they are different and should therefore be distinguished [11]. When the progress of the works run differently or less efficiently than the plan, the disruption can happen. However, projects are completed within the contract periods; the occurrence of disruption can also be experienced In other words, the completion of projects on time does not necessarily guarantee against the occurrence of disruption [12]. In construction contracts, the term 'disruption' refers to a loss of productivity due to a hindrance or interruption of the progress of the construction works which reduces the rate of efficiency.

According to a definition provided by Gibbs, Kenneth and Gordon, disruption claims can be defined as the lawful or justifiable request for more reimbursement or payment to cover the extra cost and or time required to complete a project [13]. In a very simpler expression, as penned by Ali Haider in his book 'Global Claims in Construction', disruption is defined as the hindrance to actual progress thus reduce the output of construction resources, those being primarily labor and plant [14].

Disruption is usually claimed separately from prolongation [14]. It may be present with or without prolongation. Disruption has always been very difficult to establish with a higher precision and even more difficult to ascertain in monetary terms.

Various construction claim experts has discussed the differences between delay and disruption. One of the ways to distinguished them is considering for the types of damages to be recover that comes in consequence to delay or disruption [13]. The recoverable damages they included under disruption are increased labor costs resulting from inefficiency, increased manpower employed on the project to compensate for inefficiency, increased labor costs resulting from the need to mobilize and demobilize work crews, and so on. In addition, for damages that can possibly arise from pure delay discussed as increased costs associated with an extended performance period, including increased jobsite and home office overhead, escalation of wages and material costs, equipment standby costs, extended and/or escalating finance costs, and so on.

\subsection{Disruption Damage}

Delay and disruption are not the same, but delay can cause disruption, vice versa. Disruption can occur in projects, even 
in situations where no delay has happened. Similarly, it can also take place on projects that are ahead of the schedule. Such conditions may happen, when the working scheme of the contractor is influenced and forced until shifted off the track. In such cases, if the Employer, Employer's other Contractor, the Engineer or any other body belonging to the Employer are direct cause for the occurrence of disruption or the deviation of working scheme, that party will bear the ultimate accountability for the losses comes in consequence.

Gibson in his book, described the difficulty of the estimation of disruption damage as "disruption can be widely separated in space and time from the causative event (s), but to be claimed successfully must be causally tied to their source [10]. Disruption impacts can be cumulative across large numbers of individual impacts. Disruption is fundamentally about productivity, which is hard to measure and thus rarely measured well.

Estimation of cost of disruption claims are extremely difficult, or generally impractical to attain at accurate results. The accurate quantification of the time and cost effect of such 'micro' delays or disruption claims is prevented because the role of labor/resource productivity is not fully recognized, labor productivity is not correctly measured and, finally, because the relationship between the bill of quantity (BoQ) items (cost) and program activities (time) is not transparent [15].

Disruption damage is sum of compensation money to be paid for the lost time and money due to labor inefficiency. The determination of a sum of money and EoT for the harmed party, in most instances the contractor, should not be considered as a penalty against the harming party, but as a compensation. This is to keep the relationship between the employer and the contractor smooth and healthy, and to prevent the prevalence of the sentiment of enmity. The essence of paying compensation must be aimed to bring back the impaired financial status of the claiming company to its anticipated position that will be attained if the delay or the disruption had not happened.

No payment for recovery/compensation shall be paid only with a single sheet of requisition letter, but instead must be accompanied by adequately sufficient number of contemporaneous documents that substantiate the credibility of the claim. The burden of proofing damage falls on the shoulders of the contractor/claimant. To warrant the payment of disruption costs, a contractor must identify the particular work activity that were affected by the disruption of loss of productivity and must be demonstrate that the disruption caused the contractor to incur additional costs [16].

\subsection{Measuring Disruption Damages}

Various authors' categorized methods of disruption damage quantifications into distinct categories based up on different factors. A well-known claim expert called Derek Nelson, a project manager in a UK based project management Consultancy firm, has distinguished methods of quantification of lost labor productivity into three categories [17]. These are:
Project Practice based methods

Industry based methods

Cost based methods

While Society of Contract Law, under its protocol for delay and disruption, has classified methods of measuring of lost productivity [18]. These are:

Table 1. Methods of Calculation of Disruption Damage.

\begin{tabular}{ll}
\hline Productivity base methods & Cost based methods \\
\hline Project specific studies & Estimated V Incurred labour \\
1) Measured Miles analysis & Estimated V used cost \\
2) Earned value analysis & \\
3) Program analysis & \\
4) Work or Trade Sampling & \\
5) System dynamics modelling & \\
Project Comparison studies & \\
Industry Studies & \\
\hline
\end{tabular}

Under the study, Measured Miles analysis is selected to evaluate the claimed lost labor cost due to delay and disruptions occurred by the breach of the Employer and Employer's other Contractor.

\subsubsection{Measured Miles Method}

One of the most widely accepted reference for construction claim is a protocol on Delay and Disruption launched on 2002 and updated on 2017; and prepared by Society of Construction Law [18]. It defined Measured Miles approach as: "The most appropriate way to establish disruption is to apply a technique known as 'the Measured Mile'. This compares the productivity achieved on a non-impacted part of the contract with that achieved on the impacted part. Such a comparison factors out issues concerning unrealistic programs and inefficient working The comparison can be made on the man-hours expended or the units of work performed."

Another briefing provided by Dungan, Psp and Zhao describes the Measured Miles method, a widely accepted approach involved in lost productivity claims, compares the productivities of identical or similar work between nonimpacted or least impacted and impacted segments of a project [19]. The procedure to implement a Measured Miles study usually includes data processing, productivity measurement, measured mile identification, cause and effect analysis, and loss of productivity calculation.

After the traditional measured miles approach has went through various studies and testified, experts suggested points to be considered while quantifying cost of lost labor productivity using measured miles methods. They advised that the work performed in the Measured Mile period and the alleged impacted period should:

1) Be substantially similar work in both periods;

2) Represent reasonable, attainable levels of productivity;

3) Be demonstrated based on a productivity definition of labor hours per unit (unit rate), costs or quantities of units installed;

4) Maintain the same productivity level during the Measured Mile period;

5) Have comparable skill levels involving work in both periods; 
6) Be performed on the same type and complexity of work;

7) Be performed in a similar environment compared to the environment when the affected (impact period) work was performed; and

8) Exclude from the analysis the first and last $10 \%$ of the work.

\subsubsection{Total Cost Method}

In its simplest form, the total cost method allows a claimant to establish damages by calculating the difference between its actual costs of performance, plus profit, and the contract price/bid amount. This method is very helpful to contractors because in complex construction matters it is often difficult to quantify the actual damages resulting from a delay or disruption [20].

A difficulty to estimate precise damage for the contractor, never relief the Employer from compensating. In situations where the amount of damage is quite hard to estimate but confirmed that the Employer is the cause for the disruption or the delay, a total cost method is preferred. Actually, it is the least preferred approach among all available methods. Under this method, damages are calculated by subtracting the original estimated cost for performing the entire project (the bid) from the total actual cost of the performance [21]. It can be expressed in a mathematical form as follows:

$$
\begin{gathered}
\text { Total Cost of Adjustment }=\text { As Built Price }- \\
\text { Total Contract Price }+ \text { Profit }
\end{gathered}
$$

Various courts and boards have established four necessary pre-requirements that have to be fulfilled before selecting total cost method [21, 22]. These are:

1) Absolutely no alternative method of calculating damages exists;

2) The original bid was reasonable;

3) The actual costs incurred were reasonable; and

4) The contractor was not responsible for the extra costs incurred.

\subsubsection{Modified Total Cost Method}

In order to calculate the inefficiency cost, the costs incurred due to contractor error during construction and errors in the bid price are subtracted from the total cost to determine the owner-caused damages [22]. The modified total cost method is calculated in the same manner as the total cost method. However, the contractor then deducts certain self-imposed damages from the calculated difference between the as-bid and the actual field office overhead cost. It is up to the contractor attempting to use this method identify contractor caused issues which impacted the field office overhead costs and calculate the value of the impact to the field office overhead cost [23].

This approach overcomes many of the objections to the total cost approach and has been accepted by many courts under the appropriate circumstances. Courts and boards more generally accept a variation of the Total Cost method known as the "Modified Total Cost" method. Modified Total Cost is an acceptable method when one of the Total Cost criteria is not met, but actual costs cannot be accurately determined.

Notably, the Total Cost Method cannot be used when the contractor can prove its actual costs directly by segregating them from the costs of other work. In order to reach a satisfactory level of reasonableness, adjustments to the contract price have historically included courts using the higher bid price used by a competing contractor for a certain item of work, an adjustment to the bid price to compensate for the contractor's overly optimistic productivity rate, or by averaging all bids to establish a reasonable contract price.

To reduce bid errors, an adjustment will be carried out to the bid price. In addition, unforeseen expenses of the contractor attributable to its own default, which would be considered under total cost method, will be removed from the calculation. This method is relatively acceptable method, if the conditions does not allow to employ Measured Miles approach and is preferable over total cost method.

A mathematical expression for the calculation of Modified Total Cost method is formulated by Tieder [21].

Total Cost of Adjustment $=$ Adjusted As Built Price Cost of Additional works not attributable to the OwnerAdjusted Total Contract Price + Profit

\subsection{Productivity}

Productivity can be measured as the ratio between the units of work accomplished (output) and the units of time or efforts expended (input). There are many different productivity measures. The choice between them depends on the purpose of productivity measurement and, in many instances, on the availability of data. Broadly, productivity measures can be classified as single factor productivity measures (relating a measure of output to a single measure of input) or multifactor productivity measures (relating a measure of output to a bundle of inputs) [24]. Various input and output factors are measured in terms of money and overall productivity, which measured as follows [25].

$$
\text { Productivity }=\frac{\text { Cost of Output }}{\text { Cost of Input }}
$$

\section{Methodology}

Using the Measured Mile approach, the paper tries to show all the steps the study went through to estimate a labor damage that is entitled to the contractor due to Employer's caused prolongation and disruption in both Euro and ETB currencies for the case selected for the study.

The study has followed the Measured Miles approach, which is tested and widely accepted method across the world. Due to some limitations of availability of data in the calculation of productivity, both the outputs and the inputs are taken in the form of money. Actually, expressing outputs and inputs in terms of money is not new and used to calculate productivity, as elaborated under the literature review part. The steps that has to be followed for the calculation of Measured Miles methods is explained as illustrated below:

1) The first thing that has to be done is to define the period 
of times on which the disruptions occurred due to the default of the Employer or Employer's other Contractor. But the scope of the study does not include the analysis of prolongation and disruption time. So, the periods of prolongations and disruptions taken for the purpose of the case under the study are time spans confirmed by the Employer's Representative out of proposed by the Contractor.

2) To identify the portion of affected works, adjustment factor will be setup. It can be calculated by dividing the amount of affected bill item to the total project cost.

3) Collect raw data showing costs from financial statements, for both direct and indirect costs expended regarding the labor at those affected months.

4) Collect raw data from IPCs that shows monthly payment obtained per each bill items for months claimed to be affected.

5) Putting all the collected documents in their order of precedence.

6) Calculate labor productivity for each bill items by taking the expended adjusted labor cost and payment received for that item as an output and input respectively.

7) For a better visualization, the results can be presented in a chart.

8) Using measured miles method demonstrates a productivity loss factor.

9) Finally, multiply the expended labor cost with 'adjustment factor' and 'productivity loss factor.

\section{Results and Discussions}

The case selected for the study is a prolongation and disruption claim occurred at GERDP, in which four bill items (work sections) are affected, i.e. the Main dam (MD), Right Powerhouse (RPH), Left Powerhouse (LPH) and Switchyard (SWY), which comprises $52 \%$ of the entire project value. The calculation of damage for the case using Measured Miles approach conducted as follows:

Establish Adjustment Factor - However, the initial process of MM is the time analysis to estimate the period on which the disruption and prolongation had occurred, the scope of this study does not include it and I receive these data directly from the employer representative ER.

Table 2. Periods of Disruption and Prolongation.

\begin{tabular}{|c|c|c|c|}
\hline Disruption at RPH & 17 Mar 2014 & 20 Jul 2018 & 1586 \\
\hline Prolongation at RPH & $20 \mathrm{Jul} 2018$ & 31 Mar 2019 & 254 \\
\hline Disruption at LPH & 1 May 2015 & 31 Mar 2019 & 1430 \\
\hline Disruption at SWY & 1 Jun 2014 & 12 Mar 2016 & 650 \\
\hline Prolongation at SWY & 12 Mar 2016 & 31 Mar 2019 & 1114 \\
\hline $\begin{array}{l}\text { Disruption at Main Dam due to } \\
\text { culvets }\end{array}$ & 8 Jul 2014 & 4 Jun 2015 & 331 \\
\hline $\begin{array}{l}\text { Disruption at Main Dam due to } \\
\text { Waterway U10 \&U9 and Bottom } \\
\text { Outlets }\end{array}$ & 1 May 2016 & 1 Oct 2019 & 518 \\
\hline $\begin{array}{l}\text { Prolongation at Main Dam due to } \\
\text { Waterway U10 \&U9 and Bottom } \\
\text { Outlets }\end{array}$ & 1 Oct 2017 & 31 Mar 2019 & 546 \\
\hline
\end{tabular}

Table 3. Adjustment factors.

\begin{tabular}{ll}
\hline Unaffected Work Portion & $47.98 \%$ \\
Affected Work Portion & $52.02 \%$ \\
Items & Weightage \\
Weight of MD & $38.92 \%$ \\
Weight of LPH & $4.24 \%$ \\
Weight of RPH & $8.69 \%$ \\
Weight of SWY & $0.17 \%$ \\
Total & $52.02 \%$ \\
\hline
\end{tabular}

Then among the listed 21 bill items, the affected ones by these disruption and prolongation causing events are selected and defined the weight relative to the total project. The weight of each affected work items are expressed in the table below, by dividing the amount of that bill item to the total project cost.

Estimate productivity - by using the amount of money that the company received for executing that specified work and amount of money incurred for payment of employees working under the affected work items as an output and input respectively. The calculation is carried out not only for the months on which the disruption and prolongation has experienced, but also during the normal progress periods or when the project was not disrupted. The calculated productive for the periods between Oct 2018 and Mar 2019 is shown below in the table shown below. The calculation of productivity is carried out using the formula:

$$
\text { Productivity }=\frac{\text { Payment Approved for the Works Executed }}{\text { Adjusted Salary for Employees Working under the Specified item ot sub item }}
$$

Table 4. Productivity Calculation.

\begin{tabular}{lllll}
\hline & Month & 18-Oct & 18-Nov & 18-Dec \\
\cline { 2 - 5 } RPH & Cum. Payment & $187,334,442.58$ & $188,636,285.66$ & $191,046,383.76$ \\
& Monthly Paid Amount & $3,094,387$ & $1,301,843$ & $2,410,098$ \\
& Labour Expense Incurred & $366,135.40$ & $342,042.97$ & $313,559.89$ \\
& Productivity & 8.45 & 4.02 & 7.69 \\
\hline
\end{tabular}

Compute Productivity Loss Factor (PLF) - For each work items a representative productivity recorded on both disrupted and undisturbed periods will be prepared or selected. Then to know the reduction in productivity on that specific work item due to the disruption causing events, a calculation is carried out by deducting the productivity recorded during disrupted period from that of undisrupted and convert into percentage. Here a representative productivity will be selected for both disrupted and undisrupted periods. Among the other four results a PLF 
calculation for RPH is shown below.

$$
\text { Productivity Loss Factor }=\frac{\text { Undisrupted Productivity-Disrupted Productivity }}{\text { Disrupted Productivity }} * 100 \%
$$

Table 5. Productivity Loss factor

\begin{tabular}{ll}
\hline Representative value for Undisrupted productivity & 24.32 \\
Representative value for Disrupted Prductivity & 8.62 \\
Productivity Loss Factor & $64.56 \%$ \\
\hline
\end{tabular}

Calculate Damage - An amount of money that the contractor has to be entitled for the compensation for losses in labor productivity which comes in consequence to the default of the Employer or Employer's other Contractors. It can be attained by multiplying the labor expense the claimant has expended during the disrupted period for the execution of those affected work items with the above two factors, literally adjustment factor and productivity loss factor. Then the calculation for whole affected work items will be conducted in the way explained above. The damage for the disruption occurred at Right Powerhouse for the period of 1560 days is shown in the table below.

Table 6. Damage Calculation.

\begin{tabular}{|c|c|c|c|c|c|c|c|c|c|c|}
\hline \multicolumn{11}{|c|}{ Disruption of Right PowerHouse } \\
\hline \multirow[t]{2}{*}{ Item } & \multirow[t]{2}{*}{ Cost Description } & \multirow[t]{2}{*}{ Type } & \multicolumn{2}{|l|}{ Cost } & \multirow[t]{2}{*}{$\begin{array}{l}\text { Adjustment } \\
\text { Factor } \\
\end{array}$} & \multicolumn{2}{|c|}{$\begin{array}{l}\text { Adjusted Cost for } \\
\text { Unaffected Works } \\
\end{array}$} & \multirow{2}{*}{$\begin{array}{l}\text { Ineffective } \\
\text { Period } \\
\text { Days } \\
\end{array}$} & \multicolumn{2}{|c|}{$\begin{array}{l}\text { Accrued Cost at } 30 \text { July } \\
2018\end{array}$} \\
\hline & & & ETB & Euro & & ETB & Euro & & ETB & Euro \\
\hline Item 1 & $\begin{array}{l}\text { Expatraite } \\
\text { Indirect Personnel }\end{array}$ & Daily & 62,939 & 46,636 & $4.24 \%$ & $2,666.21$ & $1,975.59$ & 1,586 & $2,730,182.26$ & $2,022,987.01$ \\
\hline Item 2 & $\begin{array}{l}\text { Local Indirect } \\
\text { Personnel }\end{array}$ & Daily & 531,719 & & $4.24 \%$ & $22,524.61$ & & 1,586 & $23,065,027.70$ & \\
\hline Item 3 & $\begin{array}{l}\text { Local Direct } \\
\text { Personnel }\end{array}$ & Daily & 62,814 & & $4.24 \%$ & $2,660.92$ & & 1,586 & $2,724,761.38$ & \\
\hline
\end{tabular}

The aggregate results for each affected work sections can be summarized as shown in the table below.

Table 7. Summary of Damage.

\begin{tabular}{lll}
\hline & Labour Damage & EURO \\
\cline { 2 - 3 } & ETB & $15,920,961.87$ \\
\hline Expatraite Indirect Labor Cost & $26,372,714.51$ & \\
Local Personnel - Indirect Labour Cost & $266,058,867.32$ & $15,920,961.87$ \\
Local Personnel - Direct Labor Cost & $25,683,316.63$ & $318,114,898.45$ \\
Total & & \\
\hline
\end{tabular}

Apply a $15 \%$ of mark up on the final result for the consideration of unabsorbed home office overhead costs.

\section{Conclusion}

The selection of approach for the estimation of damage is project specific and highly influenced by the availability of necessary data. During the estimation of the labor damage for the case under study, while calculating the productivity no labor hour data was available that would use as an input. So, an equivalent data of paid amount of money has used instead.

In order to obtain a result with a higher degree of accuracy, the data available for the computation should be adequate and shall be in a greater depth. For instance, while determining the period of time on which the project/activity was impacted, distinguishing segments of time from which the disruption causing events were not happened. If the data regarding the number of employees involved on each activities under the claim including other resource utilization information were available, it would make the calculation of lost productivity easier. Since these data were not available, the calculation for the lost productivity for the case under study was computed using the amount of money paid for labor and the income amount generated from those item within the specified period of time.
The total amount of labor damage the contractor claimed to receive as a compensation is much more higher than that of the result found under this study using a more conservative and equitable method, Measured Miles analysis. The total amount of labor damage the contractor requested for a compensation is Euro 79,094,392 and ETB 873,625,878.71, but the results found after the study is Euro 16,313,112.51 and ETB 326,294,759.90.

\section{Recommendation}

In order to attain the most accurate and precise result from the calculation of lost labor damage or the total damage, the first and the most significant step is to collect all necessary data. The quality and size of available data directly determine the accuracy of the result.

Hence, any claim expert going to estimate a damage caused due to lost productivity has to obtain a complete set of data in order to able to arrive to a better reasonable and adhering result. Moreover, it helps to reduce the occurrence of dispute emanated in consequent to biased estimates coming out from total cost and modified total cost methods.

The data required for estimation of damage shall explicitly show man-hour utilized per day or number of employees 
involved both at impacted and non-impacted periods. The amount of income generated and the expended money for that activity should be well described.

The following below are recommendations suggested by the writer:

1) In time of no adequate data is available, the calculation for estimation of productivity can be computed using monetary terms for both output and input values.

2) Other researchers may better to show a detailed and practical illustration of the mechanism of estimation of damage for materials, equipment and machineries due to disruption with step by step manner.

3) Every responsible party of any construction project better to acquire habit of developing data in a regular and professional manner.

4) Experts have to thoroughly analyze that which method is better to fit with the existing problem.

5) In some situation the available data may not allow us to conduct the computation using quantity of production and labor-hour utilized. Hence, the expert has to find some reasonably substituting available data, may be like money generated and expended.

6) The other very important thing for those who are going to compute the total compensable damage, including equipment and machineries depreciation and lost in materials, occurred on a project is highly helpful to organize a crew from variety of professions like accountants, economists, planning engineer, cost engineer, contract engineers, claim experts and may be other professional that are necessary to the team.

7) Engineers working under such restrained situation have to develop a deep insight to create alternative solution that can be reasonably accepted.

\section{References}

[1] W. Ibbs and M. Liu, "Improved measured mile analysis technique," J. Constr. Eng. Manag., vol. 131, no. 12, pp. 1249-1256, 2005, doi: 10.1061/(ASCE)07339364(2005)131:12(1249).

[2] P. J. Keane and A. F. Caletka, Delay analysis in construction contracts: 2nd edition. Wiley Blackwell, 2015.

[3] Andy Hewitt Hewitt, Construction Claims \& Responses effective writing \& presentation, vol. 1. 2016.

[4] E. K. Zaneldin, "Investigating the types, causes and severity of claims in construction projects in the UAE," International Journal of Construction Management, Taylor and Francis Ltd., 2018.

[5] A. Ness, "the Law of Construction Delay, Acceleration \& Disruption," 2010.

[6] J. G. Zack, "Delay and Delay Analysis: Isn 'T It Simple?," no. December 2005, 2006.
[7] M. R. Bin Mohamad, "THE FACTORS AND EFFECT OF DELAY IN GOVERNMENT CONSTRUCTION PROJECT (CASE STUDY IN KUANTAN)," To

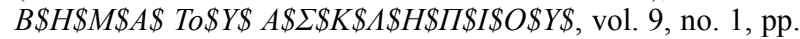
76-99, 2010, doi: 10.1558/jsrnc.v4il.24.

[8] L. C. D. and W. H. P. Nathan Chapman, "Resolving Problems and Disputes on Construction Projects: Tackling Contract Performance Delays | Lorman Education Services," 2014.

[9] R. Gemmel and M. Caswell, "Conquering Concurrency Part 1: What is concurrent delay?," pp. 1-5, 2018.

[10] R. Gibson, Construction Delays: Extensions of Time and Prolongation Claims. 2009.

[11] R. J. Gemmell, “The quantification of loss caused by disruption: How applicable is the measured mile method ?," 2015.

[12] levelset.com, "Disruption Claims | Getting Paid for Lost Productivity," 2019.

[13] Gibbs, Kenneth C. Gibbs, and Gordon Hunt, "California Construction Law - Gibbs, Kenneth C. Gibbs, Gordon Hunt Google Books," Aspen, 2009.

[14] David Chappell, Vincent Powell-Smith, and John H. M. Sims, "Building Contract Claims - David Chappell, Vincent PowellSmith, John H. M. Sims - Google Books,” Wiley, 2008.

[15] Hamish Lal, "Quantifying and Managing Disruption Claims Hamish Lal - Google Books," Thomas Telford Publishing, Thomas Telford Ltd, 1 Heron Quay, London E14 4JD. URL://www.thomastelford.com, 2002.

[16] Ali Haidar, Global Claims in Construction. Springer-Verlag London Limited, 2011.

[17] D. Nelson, "The Analysis and Valuation of Disruption," no. January, pp. 1-31, 2011.

[18] SCL, Society of Construction Law Delay and Disruption 2nd edition February 2017, no. February. 2017.

[19] T. Zhao, P. E. Psp, and M. Dungan, "CDR. 1967 Determining the Measured Mile for Lost Productivity Claims,” pp. 1-17, 2015.

[20] D. T. KNIGHT, ESQUIRE, and E. SETH M. SCHIMMEL, The Total Cost Method: An alternative theory for provng damage. 1997.

[21] J. B. Tieder, "TOTAL COST AND MODIFIED TOTAL COST CLAIMS IN THE UNITED STATES Hotel Concorde La Fayette 3 , Place du General Koenig 2 - 4 May 2013 DRBF 13th Annual International Conference \& Training Workshop," 2013.

[22] R. M. Jones, "Update on Proving and Pricing Inefficiency Claims," Constr. Lawyer, pp. 3-11, 2003.

[23] J. G. Zack and P. V. Badala, "Pricing contractor delay costs," AACE Int. Trans., vol. 2, pp. 876-894, 2012.

[24] "Measuring Productivity - OECD Manual," in Measuring Productivity - OECD Manual, 2001, doi: 10.1787/9789264194519-en.

[25] V. S. Zala, "A Study Of Productivity And Financial Efficiency Of Textile Industry Of India". 